\title{
The use of oestradiol uptake and binding-site studies in endometrial and ovarian carcinoma
}

\author{
R. W. TAYLOR \\ M.D., M.R.C.O.G.
}

M. G. BRUSH

B.Sc., M.A., PH.D.

Department of Gynaecology, St Thomas's Hospital Medical School, London S.E.1

\author{
R. J. B. KING \\ M.Sc., PH.D. \\ Imperial Cancer Research Fund, London W.C.2
}

CURRENT views on the mechanisms of oestrogen action involve specific cytoplasmic protein molecules to which oestrogen becomes bound on entering the cell. Another different receptor protein exists in the cell nucleus and oestradiol must be transferred to this second receptor before it can produce its stimulating effect (Raspé, 1971). The nature of the effect is determined by the characteristics of the cell nucleus. For example, the mechanisms by which the endometrium and the endosalpinx take up oestradiol and distribute it within the cell are identical, but the effects of the stimulation are very different.

The number of cytoplasmic (Toft, Shyamala \& Gorski, 1967) and nuclear (Anderson, Clark \& Peck, 1972) binding sites, can be estimated by in vitro studies and there is a $1: 1$ relationship between binding molecules and oestradiol molecules.

If there are no specific binding sites within a cell then it cannot be directly influenced by oestrogen. This is not to say that such cells may not be influenced indirectly, perhaps by effects upon the general metabolism or by effects upon other endocrine systems. However, these effects are likely to be marginal and we are here concerned only with the direct effect of oestradiol.

Normal endometrial cells contain 6-10,000 cytoplasmic binding sites per cell. In the follicular phase of the menstrual cycle approximately $80 \%$ of the oestradiol which a cell takes up becomes associated with the nucleus, but when progesterone is circulating during the luteal phase of the cycle only about $30 \%$ of the oestradiol becomes associated with the cell nuclei (Brush, Taylor \& King, 1967). Synthetic progestational agents produce a similar effect.

In all thirty cases of endometrial adenocarcinoma studied, oestradiol uptake and binding was seen whatever the degree of differentiation histologically, but there was considerable individual variation (Taylor et al., 1971). Sarcoma and mixed mesodermal tumours do not contain binding sites and do not respond to hormone therapy.

In eight cases of ovarian adenocarcinoma studied it has not been possible to show the presence of any specific binding sites in either the cytoplasm or the nuclei and therefore it is unlikely that there will be any dramatic response to hormone therapy.

The pronounced difference between the two tumours in respect of oestradiol binding sites can be employed to differentiate them. It is not always possible to do this either clinically or by histological examination. As endometrial carcinoma can be usefully treated with progestational agents while advanced carcinoma of the ovary is often attacked with cytotoxic drugs the task of distinguishing one from the other is not purely of academic interest.

In cases of doubtful diagnosis, in vitro studies to determine the presence or absence of specific oestradiol binding sites can lead to a more rational form of therapy.

\section{References}

Anderson, J., Clark, J.H. \& Peck, E.J. (1972) Oestrogen and nuclear binding sites. Determination of specific sites by $\left[{ }^{3} \mathrm{H}\right]$ oestradiol exchange. Biochemical Journal, 126, 561 .

Brush, M.G., TAylor, R.W. \& KING, R.J.B. (1967) The uptake of $\left[6,7^{-3} \mathrm{H}\right]$ oestradiol by the normal human female reproductive tract. Journal of Endocrinology, 39, 599.

RASPÉ, G. (Ed.) (1971). Advances in Biosciences, Vol. 7. Pergamon-Vieweg, Oxford.

TAYloR, R.W., BrUSh, M.G., KING, R.J.B. \& Witt, M. (1971) The uptake of oestrogen by endometrial carcinoma. Proceedings of the Royal Society of Medicine, 64, 407.

TofT, D., Shyamala, G. \& GorSki, J. (1967) A receptor molecule for oestrogens: studies using a cell-free system. Proceedings of the National Academy of Sciences of the United States of America, 57, 1740. 